\title{
Editorial
}

\section{Toxicity of metabolites to dopaminergic systems and the behavioural effects of organic solvents}

\begin{abstract}
Despite extensive research into the toxicity of solvents to the central nervous system (CNS), little is known about the possible mechanisms leading to behavioural changes and impairment in performance from experimental, clinical, and epidemiological investigations. ${ }^{\prime}$
\end{abstract}

Apart from a few substances which cause a well defined pattern of pathological change associated with both a peripheral neuropathy and dysfunction of the $\mathrm{CNS},{ }^{2}$ most organic solvents produce rather nonspecific effects, primarily affecting the CNS. Such effects range from depressed mood to loss of memory but the most consistent effect is represented by slow visuomotor performance or prolonged reaction times. ${ }^{3}$ Electrophysiological parameters are only slightly modified by industrial exposure to low levels of solvent mixtures and they show patterns similar to those of single solvents that are independent of their primary toxic effects. ${ }^{4}$

As a whole, these findings are intriguing and challenging, since organic solvents as a group share few physical features and even fewer chemical properties. ${ }^{5}$ None of these attributes can explain the observed effects, with the exception of the affinity for the nervous system, which is due to the fact that most solvents are strongly lipophilic. It should be recognised, however, that any changes induced in membrane fluidity would also affect the peripheral nervous system, especially the myelin sheaths, thus causing more definite changes in nerve conduction velocities than those reported so far. It should also be recognised that the brain has a tissue/blood partition coefficient comparable with the remainder of the vessel rich group. The half life of solvents in the brain is thus not expected to be longer than in other organs. As a result, the selective vulnerability of some CNS functions is not accounted for by toxicokinetic factors, although an accumulation within lipoid subcellular structures such as plasma membranes cannot be excluded. Biological half times of lipophilic solvents in such components might be longer than those expected for the whole brain. ${ }^{5}$

It seems that at present there is no common thread to account for all observed effects that solvents have on the nervous system. Indeed, there is no reason to think that there will be one in view of the considerable structural differences in the various solvents at present used in industry. ${ }^{2}$

This view is supported by the fact that similar compounds do not share metabolic pathways and, as a consequence, do not have common mechanisms of toxicity. ${ }^{6} \quad$ Furthermore some substances-for example, carbon disulphide-may produce distinct syndromes by acting through different mechanisms on multiple targets. ${ }^{2}$

Recently, it has been shown that subacute exposure to styrene causes striatal and tuberoinfundibular dopamine depletion in rabbits.' This mechanism is common to other monocyclic hydrocarbons biotransformed into metabolites having an alpha-keto acid as the lateral chain. ${ }^{6}$

The effects on brain dopamine are predictable on the basis of the chemical structure of metabolites rather than of the parent compounds. Since dopamine condenses non-enzymatically with many solvent metabolites having a reactive carbonylic group in their molecule (A Mutti et al, unpublished data), this mechanism may explain why apparently different solvents produce similar effects.

A list of the solvent metabolites that condense with dopamine in vitro to form tetrahydroisoquinolines is shown in the table. The individual metabolic pathways leading to the biotransformation into each metabolite have been described by Lauwerys, ${ }^{8}$ who also quotes original references. Interestingly, reactive intermediate metabolites of those solvents that have been shown to cause narcotic or prenarcotic effects are common, or similar to those of anaesthetic gases. For example, both enflurane and methoxyflurane give rise in vivo to oxalic acid. ${ }^{9}$ This implies a preliminary biotransformation into glyoxylic acid, an intermediate metabolite for ethylene glycol derivatives such as methylcellosolve that are widely used as organic solvents. On the other hand, halothane and fluroxene are both catabolised to trifluoroacetic acid. ${ }^{10} 11$ It is reasonable to assume that this acidic compound is produced through the formation of trifluoroacetaldehyde, which is chemically (and 
Organic solvents biotransformed into metabolites reacting with dopamine to form tetrahydroisoquinolines. A summary of relevant information on metabolic pathways may be found in Lauwerys

\begin{tabular}{|c|c|}
\hline Parent compounds & Suspected active metabolite \\
\hline $\begin{array}{l}\text { Aromatic monocyclic } \\
\text { hydrocarbons: } \\
\text { Ethylbenzene } \\
\text { Styrene } \\
\text { Vinyltoluene }\end{array}$ & Phenyglyoxylic acid \\
\hline $\begin{array}{l}\text { Chlorinated hydrocarbons: } \\
\text { Trichloroethylene } \\
\text { Perchloroethylene } \\
\text { Trichloroethane }\end{array}$ & Chloral (trichloroacetaldehyde) \\
\hline $\begin{array}{l}\text { Glycol derivatives: } \\
\text { Ethylene glycol } \\
\text { Ethylene glycol monomethyl } \\
\text { ether (methylcellosolve) }\end{array}$ & Glyoxylic acid \\
\hline $\begin{array}{l}\text { Alcohols: } \\
\text { Methanol } \\
\text { Ethanol }\end{array}$ & $\begin{array}{l}\text { Formaldehyde } \\
\text { Acetaldehyde }\end{array}$ \\
\hline
\end{tabular}

probably pharmacologically) similar to chloral (trichloroacetaldehyde) - that is, a major intermediate metabolite of various chlorinated hydrocarbons having narcotic properties.

Thus from a metabolic point of view, there are striking similarities between anaesthetic gases and some solvents which are known to produce acute neurobehavioural effects. The fact that all reactive metabolites of the above solvents recognise dopamine as a selectively vulnerable target suggests that dopamine depletion (due to its condensation to form tetrahydroisoquinolines) may have a role in solvent toxicity to the CNS. Further experimental work should confirm that the same reactions also occur in vivo. Both glyoxylic and phenylglyoxylic acids, however, are effective in causing dopamine depletion ${ }^{12}$ and a similar reaction leading to formation of tetrahydroisoquinolines may be obtained by using chloral (A Mutti et al, unpublished data).

That the same mechanism operates in man is suggested by consistent neuroendocrine changes in occupationally exposed laminators. ${ }^{1314}$ Whereas other dopaminergic pathways are protected by the blood/ brain barrier and may be affected only by those hydrophilic substances that are formed in situ, the tuberoinfundibular dopaminergic system (TIDA) may represent a target for metabolites dissolved in the blood stream. This might imply a selective vulnerability of pituitary functions, which are modulated by TIDA activity; dramatic changes in PRL secretion have been found in workers occupationally exposed to styrene. ${ }^{1314}$ Prolactin is, however, just one of the hormones controlled by dopaminergic pathways. A wider range of perturbations in pituitary functions has also been shown. ${ }^{13}$ Furthermore, several monoamines and peptides interact with the hypothalamic dopamin- ergic neurons. ${ }^{1516}$ An impairment of tuberoin fundibular dopaminergic activity might explain mos of the known behavioural changes induced by styrene: and perhaps by other solvents sharing a common toxi $\overrightarrow{\vec{\rho}}$ mechanism.

Little is known about the possible effects of tetrahydroisoquinolines but they probably have botto. pharmacological and toxic properties. For instancep salsolinol and carboxysalsolinol, which are tetra hydroisoquinolines formed by the condensation of dopamine with acetaldehyde and pyruvic acid, respece $\vec{\bullet}$ tively, seem to be responsible for behavioural changes. in alcoholics. ${ }^{17}$

Since it is now accepted that occupational exposuro to organic solvents may induce some behavioura\$ disturbances, which in turn may arise from a range of different mechanisms, it seems justified to focus atten: tion on more specific neuroendocrine effects. The advantage of such an approach relates to the specificity of the neurochemical mechanisms controll $\vec{b}$ ing pituitary secretion. Although these mechanisms may also be affected by confounding or modifying factors, several extraneous variables such as educational and cultural background may be ruleథ out. This allows for the exploration of causal rathe than multifactorial relations between solvent exposure and CNS dysfunction. Furthermore, such approach may be valuable for the study of other effe्st $t\}^{\circ}$ of solvent exposure, such as those on sexual behavisug and reproductive toxicity. The evidence now stroritio suggests that the major pathways that are affected in the hypothalamic control of gonadotropins ie primates are adrenergic and dopaminergic. ${ }^{18}$

Although neuroactive drugs are known to induce

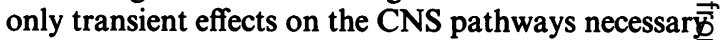
for normal gonadotropin secretion, occupationa exposure to neurotoxins may cause repeated reversible effects, which are difficult to distinguish from chronie. effects because of the chronic nature of exposure. Afteg even short term exposures, a complete recovery of neuroendocrine changes would require severas weeks. $^{14}$

Questions remaining to be answered include the rol\& of a possible tolerance, which is known to develop, fo instance, during chronic alcohol abuse. ${ }^{17}$ In this case? however, a complicated pattern may result from liver damage and liver dysfunction. ${ }^{1920}$ In worker occupationally exposed to styrene, there is evidence of a relation between recent exposure and measurable effects on the CNS. ${ }^{1314152122}$ As a result, at least in thiß occupational setting, the fact that prolonged exposure్ట induces tolerance may be ruled out. An even more important question is the importance of such effects with regard to the long term prognosis of worker exposed to solvents. A satisfactory answer is not ye? available, though an excess of risk for Alzheimer's 
disease and presenile dementia of the Alzheimer's type has been excluded by recent epidemiological investigations. ${ }^{23}$ This does not necessarily mean, however, that workers exposed to solvents do not suffer from irreversible or slowly reversible cognitive and neuropsychological impairment.

A MUTTI

I FRANCHINI

Institute of Clinical Medicine and Nephrology,

Section of Occupational Medicine and

Laboratory of Industrial Toxicology,

University of Parma,

I-43100 Parma, Italy.

\section{References}

1 Cranmer JM, Golberg L, eds. Proceedings of the workshop on neurobehavioural effects of organic solvents. Neurotoxicology 1986;7.

2 Cavanagh JB. Mechanisms of organic solvent toxicity: morphological changes. In: Chronic effects of organic solvents on the central nervous system and diagnositic criteria. Copenhagen: World Health Organisation, 1985:110-35. (Environmental health series No 5.)

3 Gamberale F. The use of behavioural performance tests in the assessment of solvent toxicity. Scand J Work Environ Health 1985;11:65-74.

4 Seppalainen AM. Neurophysiological aspects on toxicity of organic solvents. Scand J Work Environ Health 1985;11:61-4

$5 \mathrm{Cohr}$ KH. Definition and practical limitation of the concept organic solvents. In: Chronic effects of organic solvents on the central nervous system and diagnostic criteria. Copenhagen: World Health Organisation, 1985:43-55. (Environmental health series No 5.)

6 Romanelli A, Falzoi M, Mutti A, et al. Effects of some monocyclic aromatic solvents and their metabolites on brain dopamine in rabbits. J Appl Toxicol 1986;6:431-5.

7 Mutti A, Falzoi M, Romanelli A, Franchini I. Regional alterations of brain catecholamines by styrene exposure in rabbits. Arch Toxicol 1984;55:173-7.

8 Lauwerys RR. Industrial chemical exposure: guidelines for biological monitoring. Davis, California: Biomedical Publications, 1983.
9 Dahlgren BE. Fluoride concentrations in urine of delivery ward personnel following exposure to low concentrations of methoxyflurane. J Occup Med 1979;21:624-6.

10 Cohen EN, Trudel JR, Emunds HN, Watson E. Urinary metabolites of halothane in man. Anesthesiology 1975;43:382-5.

11 Holaday DA, Fiserova-Bergerova V. Fate of fluorinated metabolites of inhalation anesthetics in man. Drug Met Rev 1979;9:61-72.

12 Mutti A, Romanelli A, Falzoi M, et al. Styrene metabolism and striatal dopamine depletion in rabbits. Arch Toxicol 1985;suppl 8:447-50.

13 Mutti A, Vescovi PP, Falzoi M, et al. Neuroendocrine effects of styrene in occupationally-exposed workers. Scand $J$ Work Environ Health 1984;10:225-8.

14 Arfini G, Mutti A, Vescovi PP, et al. Impaired dopaminergic modulation of pituitary secretion in workers occupationallyexposed to styrene: further evidence from PRL response to TRH stimulation. J Occup Med (in press).

15 Fuxe K, Andersson K, Hokfelt T, et al. Localization and possible function of peptidergic neurons and their interactions with central catecholamine neurons and the central action of gut hormones. Fed Proc 1979;38:2333-40.

16 Dent RRM, Guilleminault C, Albert LH, et al. Diurnal rhythm of plasma immunoreactive B-endorphin and its relationship to sleep stages and plasma levels of cortisol and prolactin. Journal of Endocrinology Metabolism 1981;52:942-6.

17 Sjoquist B, Ljungquist C. Identification and quantification of 1carboxy-salsolinol and salsolinol in biological samples by gaschromatography-mass spectrometry. J Chromatogr 1985;343:1-8.

18 Smith CG. Reproductive toxicity: hypothalamic-pituitary mechanisms. Am J Ind Med 1983;4:107-12.

19 Gordon GG, Altman K, Southern AL, et al. Effect of alcohol (ethanol) administration on sex-hormone metabolism in normal man. N Engl J Med 1976;295:793-7.

20 Gordon GG, Southern AL, Lieber CS. The effects of alcoholic liver disease and alcohol ingestion on sex hormone levels. Alcoholism: Clinical and Experimental Research 1978;2:259-63.

21 Mutti A, Mazzucchi A, Rustichelli P, et al. Exposure-effect and exposure-response relationships between occupational exposure to styrene and neuropsychological functions. Am J Ind Med 1984;5:275-86.

22 Cherry N, Waldron HA, Wells GG, et al. An investigation on acute behavioural effects of styrene on factory workers. Br J Ind Med 1980;37:234-40.

23 O'Flynn RR, Monkman SM, Waldron HA. Organic solvents and presenile dementia: a case-referent study using death certificates. Br J Ind Med 1987;44:259-62. 